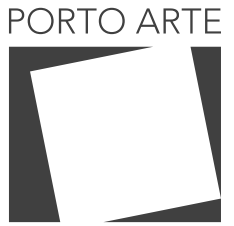

Revista de Artes Visuais

v. $25 \mathrm{n} .43$

Jan/jun 2020

e-ISSN: 2179-8001

\title{
Imagem / Palavra / Imagem
}

Image / Word / Image

\section{Maria Teresa Kerr Saraiva}

ORCID: 0000-0002-6875-0153

Universidade de São Paulo, Brasil

\section{Resumo}

Disputa entre a palavra e a imagem artística. Primazia da primeira. Elementos racionais rígidos, estanques. Fortes entraves. Luta. Aos poucos o ambiente se pacifica. A imagem vai se impondo, vitoriosa, numa harmoniosa e equilibrada dança.

Palavras-chave

Palavra. Imagem artística. Disputa. Colagem

\section{Abstract}

Dispute between the word and the artistic image. Primacy of the first. Rigid and stanching rational elements. Strong barriers. Fight. Gradually the environment pacifies. The image imposes itself, victorious, in a harmonious and balanced dance.

Word. Artistic image. Dispute. Collage. 


$$
\sqrt{2}
$$




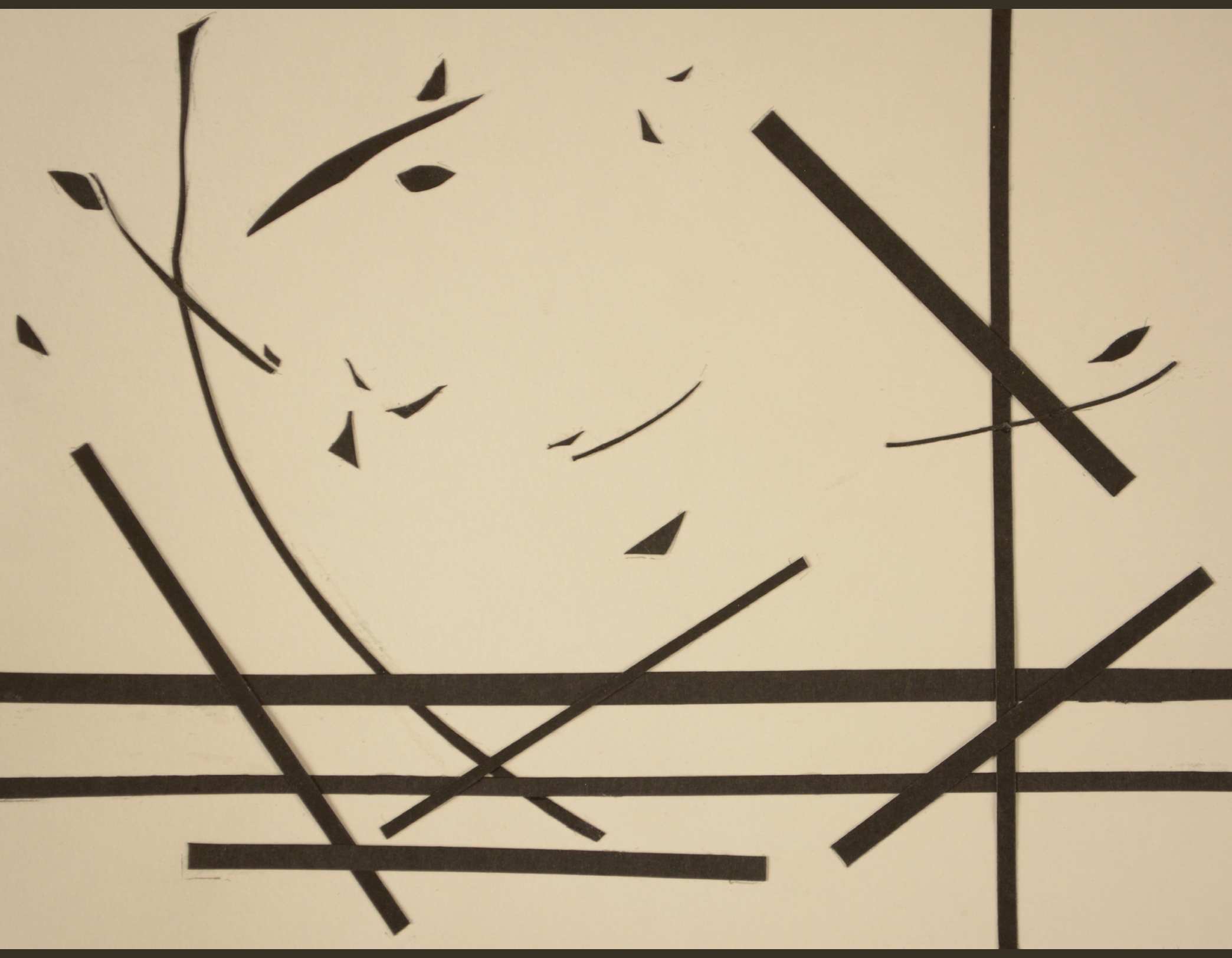




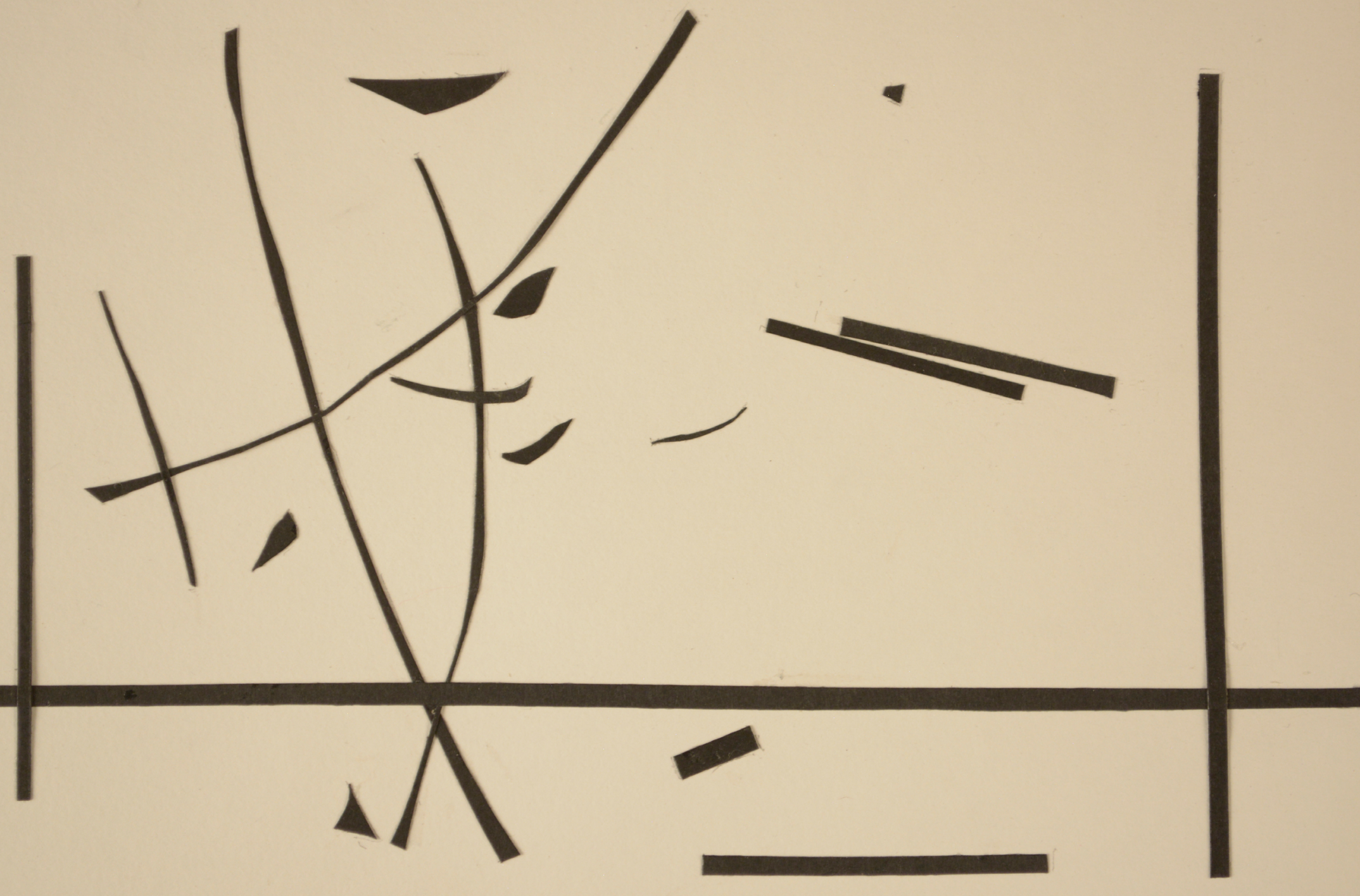




$$
\stackrel{y}{7}
$$




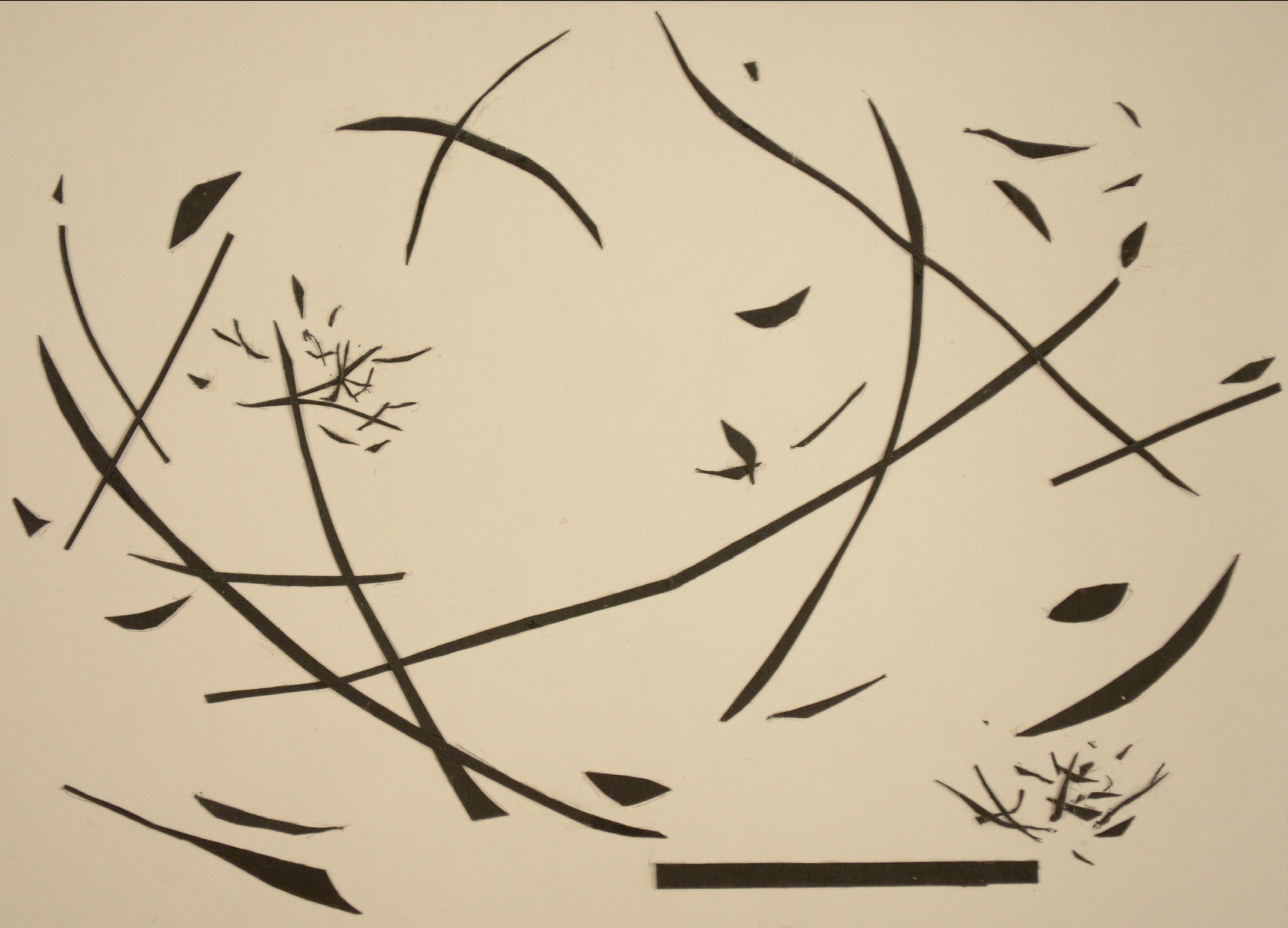




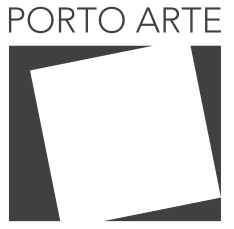

Revista de Artes Visuais

v. 25 ก. 43

\section{Maria Teresa Kerr Saraiva}

Arquiteta e Artista plástica. Professora Faculdade de Arquitetura e Urbanismo da Universidade de São Paulo, onde leciona desde 2014. Exposições e livros de Desenho "Traços Urbanos" (2004), "Traços de Itu" (2012 e 2014), Traços de Paranapiacaba (2017) e a obra pública "Painel Estação da Luz" (2006). 